Article

\title{
Pharmacokinetic and Metabolism Studies of 12-Riboside-Pseudoginsengenin DQ by UPLC-MS/MS and UPLC-QTOF-MS ${ }^{\mathrm{E}}$
}

\author{
Zhenzhou Wang, Hongqiang Lin, Hailin Zhu, Na Yang, Baisong Zhou, Cuizhu Wang, Pingya Li * \\ and Jinping Liu *iD \\ School of Pharmaceutical Sciences, Jilin University, Fujin Road 1266, Changchun 130021, China; \\ wzz16@mails.jlu.edu.cn (Z.W.); linhq17@mails.jlu.edu.cn (H.L.); \\ 13578965875@163.com (H.Z.);yangn0227@163.com (N.Y.); zhoubs16@mails.jlu.edu.cn (B.Z.); \\ wangcz15@mails.jlu.edu.cn (C.W.) \\ * Correspondence: lipy@jlu.edu.cn (P.L.); liujp@jlu.edu.cn (J.L.); Tel.: +86-431-8561-9803 (P.L. \& J.L.)
}

Received: 7 September 2018; Accepted: 26 September 2018; Published: 29 September 2018

\begin{abstract}
Pharmacokinetic and metabolism studies of 12-riboside-pseudoginsengenin DQ (RPDQ), a novel ginsenoside with an anti-cancer effect, were carried out, aiming at discussing the characteristics of the ginsenoside with glycosylation site at C-12. In the pharmacokinetic analysis, we developed and validated a method by UPLC-MS to quantify RPDQ in rat plasma. In the range of $5-1000 \mathrm{ng} / \mathrm{mL}$, the assay was linear $\left(R^{2}>0.9966\right)$, with the LLOQ (lower limit of quantification) being $5 \mathrm{ng} / \mathrm{mL}$. The LOD (limit of detection) was $1.5 \mathrm{ng} / \mathrm{mL}$. The deviations of intra-day and inter-day, expressed as relative standard deviation (RSD), were $\leq 3.51 \%$ and $\leq$ $5.41 \%$ respectively. The accuracy, expressed as relative error (RE), was in the range $-8.82 \sim 3.47 \%$ and $-5.61 \sim 2.87 \%$, respectively. The recoveries were in the range $85.66 \sim 92.90 \%$. The method was then applied to a pharmacokinetic study in rats intragastrically administrated with 6,12 , and $24 \mathrm{mg} / \mathrm{kg}$ RPDQ. The results showed that RPDQ exhibited slow oral absorption ( $T_{\max }=7.0 \mathrm{~h}$, $7.5 \mathrm{~h}$, and $7.0 \mathrm{~h}$, respectively), low elimination $\left(t_{1 / 2}=12.59 \mathrm{~h}, 12.83 \mathrm{~h}\right.$, and $13.74 \mathrm{~h}$, respectively) and poor absolute bioavailability $(5.55,5.15$, and $6.08 \%$, respectively). Moreover, the investigation of metabolites were carried out by UPLC-QTOF-MS. Thirteen metabolites of RPDQ were characterized from plasma, bile, urine, and feces of rats. Some metabolic pathways, including oxidation, acetylation, hydration, reduction, hydroxylation, glycine conjugation, sulfation, phosphorylation, glucuronidation, glutathione conjugation, and deglycosylation, were profiled. In general, both the rapid quantitative method and a good understanding of the characteristics of RPDQ in vivo were provided in this study.
\end{abstract}

Keywords: 12-riboside-pseudoginsengenin DQ; pharmacokinetics; metabolism; UPLC-MS

\section{Introduction}

Ginseng, a traditional Chinese medicine, has been widely used. Ginsenosides are the main active ingredient $[1,2]$. According to the skeleton of sapogenin, ginsenosides can be divided into tetracyclic and pentacyclic triterpene types [3,4]. The former type could be divided into dammarane-subtype and ocotillol-subtype saponins [5]. It is worth mentioning that ocotillol-type saponin (20, 24-epoxyside) has many high activities such as neuroprotective, antiinflammatory, antibacterial, and antitumor effect [6-9]. The discovery of this type showed that the natural ones were mainly existed in American ginseng, Vietnam ginseng, or Panax japonicas [10-12]. Recently, the semisynthesis has been receiving more and more attention aiming to increase the yields or obtain the novel ocotillol-type saponin [13-16]. 
In our study, a novel ocotillol-type ginsenoside, named 12-riboside-pseudoginsengenin DQ (RPDQ), was semi-synthesized successfully by glycosylation reaction of pseudoginsengenin DQ. It was structurally characterized as 20S, 24S-12-O- $\beta$-D-ribofuranosyl-dammar-20, 24-epoxy-3 $\beta, 12 \beta, 25$-triol with HR-MS and NMR analysis (Supplementary Material 1) and showed a significant anticancer activity against S180 cells, A549 cells, and SPC-A-1 cells in vitro (Supplementary Material 2).

So far, there have been some pharmacokinetic study on sapogenins and ginsenosides. Among the most commonly measured pharmacokinetic parameters, some of the characteristics such as elimination half-life $\left(t_{1 / 2}\right)$ and bioavailability $(F)$ are various for different saponins after intragastric administration. For example, protopanaxdiol takes less time $\left(t_{1 / 2}: 1.48 \mathrm{~h}\right)$ to reach half the concentration of the original value and a higher bioavailability (F: 36.8\%) [17]. However, pseudoginsengenin DQ, the ocotillol-type sapogenin prepared by oxidative cyclization of protopanaxadiol, has a longer biological half time $\left(t_{1 / 2}: 5.97 \mathrm{~h}\right)$ [18]. On the other hand, for different structure types of ginsenoside, there are many differences in pharmacokinetic characteristics. Ginsenosides $\mathrm{Rb}_{1}, \mathrm{Rb}_{2}$, and $\mathrm{R} \mathrm{b}_{3}$, with the glycoside position being C-3, had a longer biological half time $\left(t_{1 / 2}: 9.8 \mathrm{~h}, 23.1 \mathrm{~h}\right.$, and $21.1 \mathrm{~h}$, respectively) and extremely low bioavailability $(0.78,0.08$, and $0.52 \%$, respectively) [19]. Ginsenoside CK, with the glycoside position being C-20, has a better bioavailability (4.30\%) [20]. In addition, ginsenosides $\mathrm{Rg}_{1}$ and $\mathrm{Rh}_{1}$, with the glycoside position being $\mathrm{C}-6$, also have poor bioavailabilities $(1.33$ and $1.01 \%)$ [21,22]. Moreover, the $t_{1 / 2}(0.43 \mathrm{~h})$ of $\mathrm{Rh}_{1}$ was substantially low [23]. Consequently, the pharmacokinetic characteristics are closely related to the structures of compounds. The glycoside positions of ginsenosides found in pharmacokinetic studies have all been C-3, C-6, and C-20, while those found in pharmacokinetic studies on ginsenosides with glycosylation site at C-12 remain blank.

In this study, RPDQ was used to carry out pharmacokinetic and metabolism studies. A sensitive and rapid UPLC-MS/MS quantification method has been developed and validated. The method was then applied to a pharmacokinetic study in rats administrated with RPDQ. Metabolic characterization of RPDQ was also carried out to explicate the dynamic process of RPDQ in vivo. The aim was to discuss the pharmacokinetic and metabolism characteristics of the ginsenoside with a glycosylation site at C-12. In general, a rapid quantitative method and a good understanding of the characteristics of RPDQ in vivo are provided in this study.

\section{Results}

\subsection{Pharmacokinetic Study}

\subsubsection{Method Development}

Different sample pre-treatment methods including protein precipitation, liquid-liquid, or solid-phase extraction were comparatively investigated to minimize the matrix effect and increase the extraction recovery. As a result, the method of precipitating protein by methanol was chosen. In order to increase the sensitivity of the RPDQ and IS, $0.1 \%$ formic acid was added to the mobile phase. In the current conditions, there was no significant signal enhancement or inhibition was found. Several possible internal standards, including 20R-panaxadiol, ocotillol and protopanaxdiol, were tested. Ocotillol was considered as IS, while the retention time of it was not satisfactory under the analysis condition. Protopanaxdiol had a low sensitivity. The extraction efficiency and chromatographic behavior of 20R-panaxadiol was similar to RPDQ, so it was selected as the IS. Due to the similar structures, RPDQ, and 20R-panaxadiol could all produce strong signals in the ESI ${ }^{+}$ mode. $\mathrm{ESI}^{+}$mode was finally used to detect RPDQ after both the $\mathrm{ESI}^{+}$mode and the $\mathrm{ESI}^{-}$mode being tested. Other parameters were also screened for ionization optimization. Full-scan product ion spectra of the $[\mathrm{M}+\mathrm{H}]^{+}$ions and the fragmentation pathways of RPDQ and IS are shown in Figure 1. Precursor ion and product ions were chosen according to the stability and ion response. The transition $m / z$ 609.4348 $\rightarrow 143.1068$ and $461.3941 \rightarrow 127.1119$ were chosen for the quantitation of RPDQ and IS, respectively. 
(A)

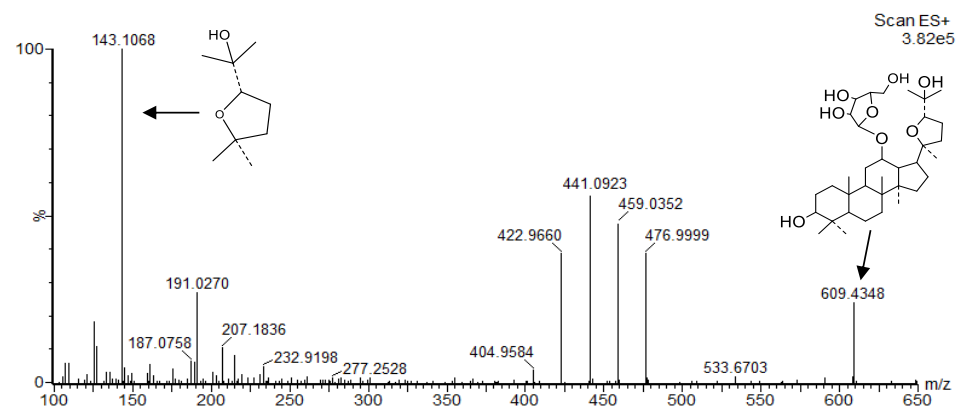

(B)

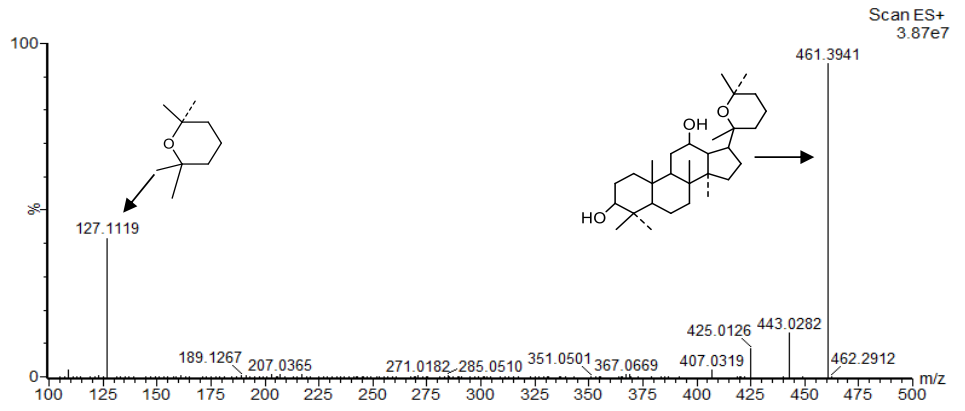

Figure 1. Mass spectra and the proposed patterns of fragmentation of RPDQ (A) and internal standard (IS) (B).

\subsubsection{Method Validation}

There was high selectivity in the detection of the RPDQ (RT, $1.38 \mathrm{~min}$ ) and IS (RT, $1.51 \mathrm{~min}$ ) by MRM without significant endogenous interference. Typical chromatograms of a blank plasma sample (A), a blank plasma sample spiked with the analytes at $300 \mathrm{ng} / \mathrm{mL}$ and IS at $100 \mathrm{ng} / \mathrm{mL}$ (B), and a plasma sample (RPDQ, $1000 \mathrm{ng} / \mathrm{mL}$ ) collected at $6 \mathrm{~h}$ after an oral dose of $12 \mathrm{mg} / \mathrm{kg}$ RPDQ (C) are shown in Figure 2.

(A)

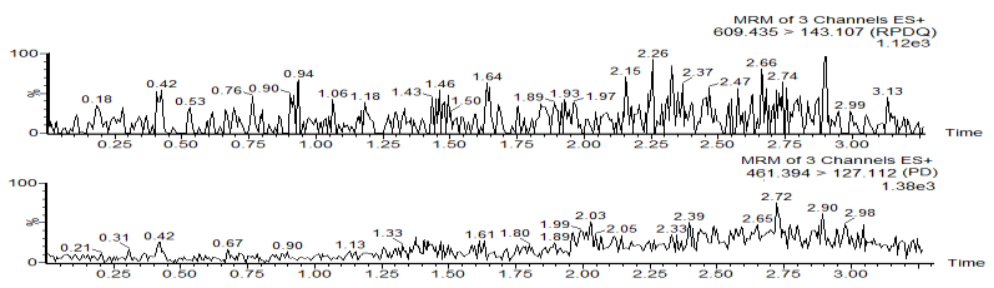

(B)

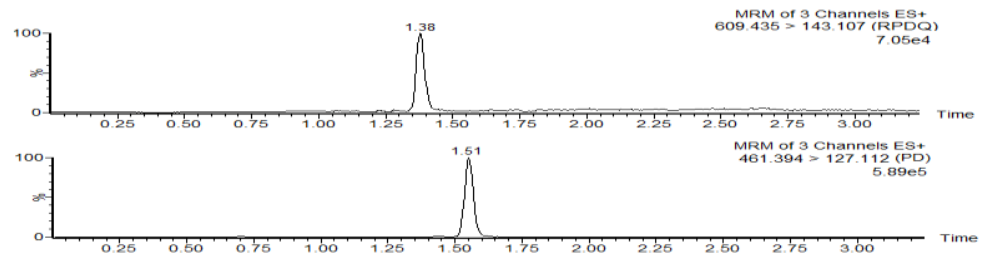

(C)

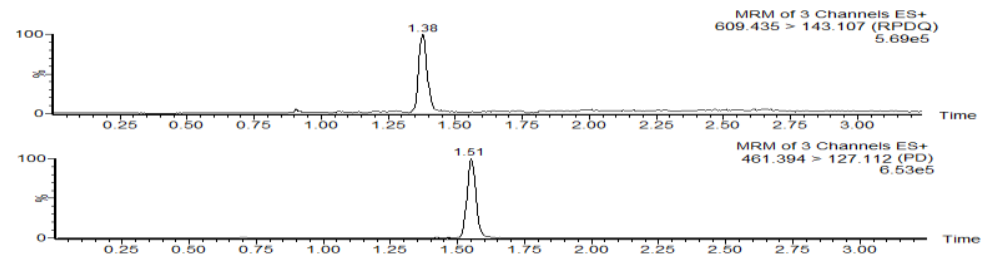

Figure 2. Representative chromatograms of (A) blank plasma, (B) blank plasma spiked with RPDQ and IS, and (C) a real plasma sample collected at an oral dose of $12 \mathrm{mg} / \mathrm{kg}$ RPDQ.

High linearity could be observed from the standard calibration curve ranging from 5 to $1000 \mathrm{ng} / \mathrm{mL}$ for RPDQ $\left(r^{2}=0.9966\right)$. The LLOQ was $5 \mathrm{ng} / \mathrm{mL}$, which was already adequate for 
the detection of RPDQ in the pharmacokinetic study. The intra-day and inter-day precision was $1.51 \sim 3.51 \%$ and $2.23 \sim 5.41 \%$, respectively. The intra-day and inter-day accuracy ranged from $-5.61 \%$ to $2.87 \%$ and from -8.82 to $3.47 \%$, respectively (Table 1). The variation of the IS measurements was less than $15 \%$.

Table 1. Intra-day and inter-day precision and accuracy of RPDQ in rat plasma.

\begin{tabular}{ccccccc}
\hline $\begin{array}{c}\text { Concentration } \\
\text { (ng/mL) }\end{array}$ & $\begin{array}{c}\text { Inter-Day Measured } \\
\text { Concentration } \\
\text { (ng/mL) }\end{array}$ & $\begin{array}{c}\text { Precision } \\
\text { (RSD, \%) }\end{array}$ & $\begin{array}{c}\text { Accuracy } \\
\text { (RE, \%) }\end{array}$ & $\begin{array}{c}\text { Intra-Day Measured } \\
\text { Concentration } \\
\text { (ng/mL) }\end{array}$ & $\begin{array}{c}\text { Precision } \\
\text { (RSD, \%) }\end{array}$ & $\begin{array}{c}\text { Accuracy } \\
\text { (RE, \%) }\end{array}$ \\
\hline 15 & $15.52 \pm 0.84$ & 5.41 & 3.47 & $15.43 \pm 0.55$ & 3.51 & 2.87 \\
200 & $182.41 \pm 6.87$ & 3.48 & -8.82 & $188.79 \pm 3.56$ & 1.79 & -5.61 \\
800 & $775.02 \pm 17.75$ & 2.23 & -3.12 & $788.99 \pm 12.04$ & 1.51 & -1.3 \\
\hline
\end{tabular}

The best recovery of RPDQ was obtained by using protein-precipitating method. The recoveries of RPDQ at 15, 200, and $800 \mathrm{ng} / \mathrm{mL}$ were $92.90 \pm 5.32,85.66 \pm 4.93$, and $87.33 \pm 1.68 \%$, respectively. The recovery of the IS was $89.41 \pm 5.21 \%$. It was shown that the preparation efficiency of RPDQ and IS in the study was acceptable.

The matrix effect for RPDQ or IS was assessed by using QC plasma samples $(15,200$, and $800 \mathrm{ng} / \mathrm{mL})$ or using 20R-panaxadiol sample $(80 \mathrm{ng} / \mathrm{mL})$. The average matrix effect values were $85.11 \pm 2.42$, $93.06 \pm 4.78$, and $84.76 \pm 3.68 \%$ for RPDQ at three QC concentrations, respectively. The matrix effect on IS was $95.15 \pm 2.49 \%$ at the tested concentration.

The stability results (Table 2 ) showed that RPDQ was stable after it was placed at $25^{\circ} \mathrm{C}$ for $4 \mathrm{~h}$ or at $-20^{\circ} \mathrm{C}$ for 14 days, or after experiencing three freeze-thaw ( -20 to $25^{\circ} \mathrm{C}$ ) cycles. The results of diluted reliability are shown in Table 3 , suggesting that the dilution did not affect the quantitative results of plasma samples.

Table 2. The stability of RPDQ in rat plasma $(n=6)$.

\begin{tabular}{ccccc}
\hline & \multicolumn{2}{c}{ Concentration } & Mean & Accuracy \\
\cline { 2 - 5 } & \multicolumn{2}{c}{$(\mathbf{n g} / \mathbf{m L})$} & $\mathbf{( n g} / \mathbf{m L})$ & $\mathbf{( \% )}$ \\
\hline Short-term stability & & 15 & $14.85 \pm 0.72$ & -1.00 \\
$\left(25^{\circ} \mathrm{C}, 4 \mathrm{~h}\right)$ & $\mathrm{RPDQ}$ & 200 & $188.12 \pm 14.00$ & -5.94 \\
& & 800 & $773.99 \pm 26.01$ & -3.25 \\
& $\mathrm{IS}$ & 100 & $92.34 \pm 3.12$ & -7.66 \\
\hline Long-term stability & \multirow{2}{*}{$\mathrm{RPDQ}$} & 15 & $15.33 \pm 1.61$ & 2.2 \\
$\left(10^{\circ} \mathrm{C}, 16 \mathrm{~h}\right)$ & & 800 & $186.96 \pm 13.41$ & -6.52 \\
& $\mathrm{IS}$ & 100 & $91.23 \pm 15.82$ & 2.03 \\
& & 15 & $15.41 \pm 2.31$ & -8.66 \\
\hline Freezing stability & $\mathrm{RPDQ}$ & 200 & $179.07 \pm 14.73$ & -10.47 \\
$\left(-20^{\circ} \mathrm{C}, 14 \mathrm{~d}\right)$ & & 800 & $786.32 \pm 19.88$ & -1.71 \\
& $\mathrm{IS}$ & 100 & $94.74 \pm 4.25$ & -5.26 \\
\hline Freeze-thaw & & 15 & $14.96 \pm 0.58$ & -0.03 \\
stability & $\mathrm{RPDQ}$ & 200 & $188.7 \pm 16.57$ & -5.65 \\
(freeze-thaw & & 800 & $785.21 \pm 19.19$ & -1.85 \\
cycles) & IS & 100 & $94.11 \pm 3.47$ & -5.89 \\
\hline
\end{tabular}

Table 3. The diluted reliability of RPDQ in plasma $(n=6)$.

\begin{tabular}{cccc}
\hline Concentration after Dilution $(\mathbf{n g} / \mathbf{m L})$ & Mean $(\mathbf{n g} / \mathbf{m L})$ & Accuracy $(\%)$ & RSD $(\%)$ \\
\hline 15 & $14.82 \pm 0.61$ & -1.20 & 4.11 \\
200 & $187.79 \pm 12.19$ & -6.11 & 6.49 \\
800 & $784.17 \pm 21.17$ & -1.98 & 2.70 \\
\hline
\end{tabular}




\subsubsection{Pharmacokinetic Study}

The established method was then applied in a pharmacokinetic study of RPDQ after oral and intravenous administration in the present study. All of the data were calculated by the statistical software of DAS 3.0. (Shanghai Bojia Pharmatech Co.Ltd., Shanghai, China). From the results of concentration-time profiles (Figure 3) and the main pharmacokinetic parameters (Table 4), it was concluded that RPDQ was slowly cleared $\left(C L, 0.04 \pm 0.001 \mathrm{~L} / \mathrm{h} / \mathrm{kg} ; t_{1 / 2}, 2.94 \mathrm{~h}\right)$ and high extravascular distribution $\left(V_{\mathrm{d}}, 11.52 \pm 0.02 \mathrm{~L} / \mathrm{kg}\right)$ after intravenous administration. On the other hand, RPDQ was detected at the first sample collection time $(0.25 \mathrm{~h})$ and reached the peak concentration at $7.25 \mathrm{~h}$ after oral administration. It was suggested that RPDQ was absorbed very slowly through the gastrointestinal tract. Moreover, the RPDQ exhibited slowly elimination $\left(t_{1 / 2}, 12.83 \mathrm{~h}\right)$ from plasma, and it could still be quantified in plasma at $60 \mathrm{~h}$ after gastrointestinal administration. As well as the low values of AUC, the mean of $F$ was $5.15 \%$. It was indicated that the analytical method applied to the pharmacokinetic study of RPDQ in rats was suitable and sufficient. In a word, the characteristic pharmacokinetic properties of RPDQ included slow oral absorption, low clearance, and poor absolute bioavailability.

Table 4. Pharmacokinetic parameters after intragastric or intravenous administration in rats.

\begin{tabular}{|c|c|c|c|c|c|c|c|}
\hline $\begin{array}{c}\text { Dose } \\
(\mathrm{mg} / \mathrm{kg})\end{array}$ & $t_{1 / 2}(\mathrm{~h})$ & $T_{\max }(\mathrm{h})$ & $\mathrm{AUC}_{(0-60)}(\mathrm{ug} / \mathrm{L} / \mathrm{h})$ & $\operatorname{AUC}_{(0-\infty)}(\mathrm{ug} / \mathrm{L} / \mathrm{h})$ & F (\%) & Vz (L/kg) & $\begin{array}{c}\text { CLz } \\
(\mathrm{L} / \mathrm{h} / \mathrm{kg})\end{array}$ \\
\hline 6 & $12.59 \pm 1.28$ & $7.0 \pm 1.55$ & $9212.53 \pm 608.41$ & $9568.25 \pm 545.64$ & $5.55 \%$ & $11.45 \pm 1.55$ & $0.63 \pm 0.036$ \\
\hline 24 & $13.74 \pm 1.11$ & $7.0 \pm 1.55$ & $40,358.37 \pm 3441.44$ & $42,553.53 \pm 3207.59$ & $6.08 \%$ & $11.28 \pm 1.69$ & $0.57 \pm 0.044$ \\
\hline 0.3 (i.v) & $2.94 \pm 0.51$ & 0.25 & $8298.18 \pm 258.5$ & $8325.73 \pm 270.09$ & - & $11.52 \pm 0.02$ & $0.04 \pm 0.001$ \\
\hline
\end{tabular}


(A)

(B)
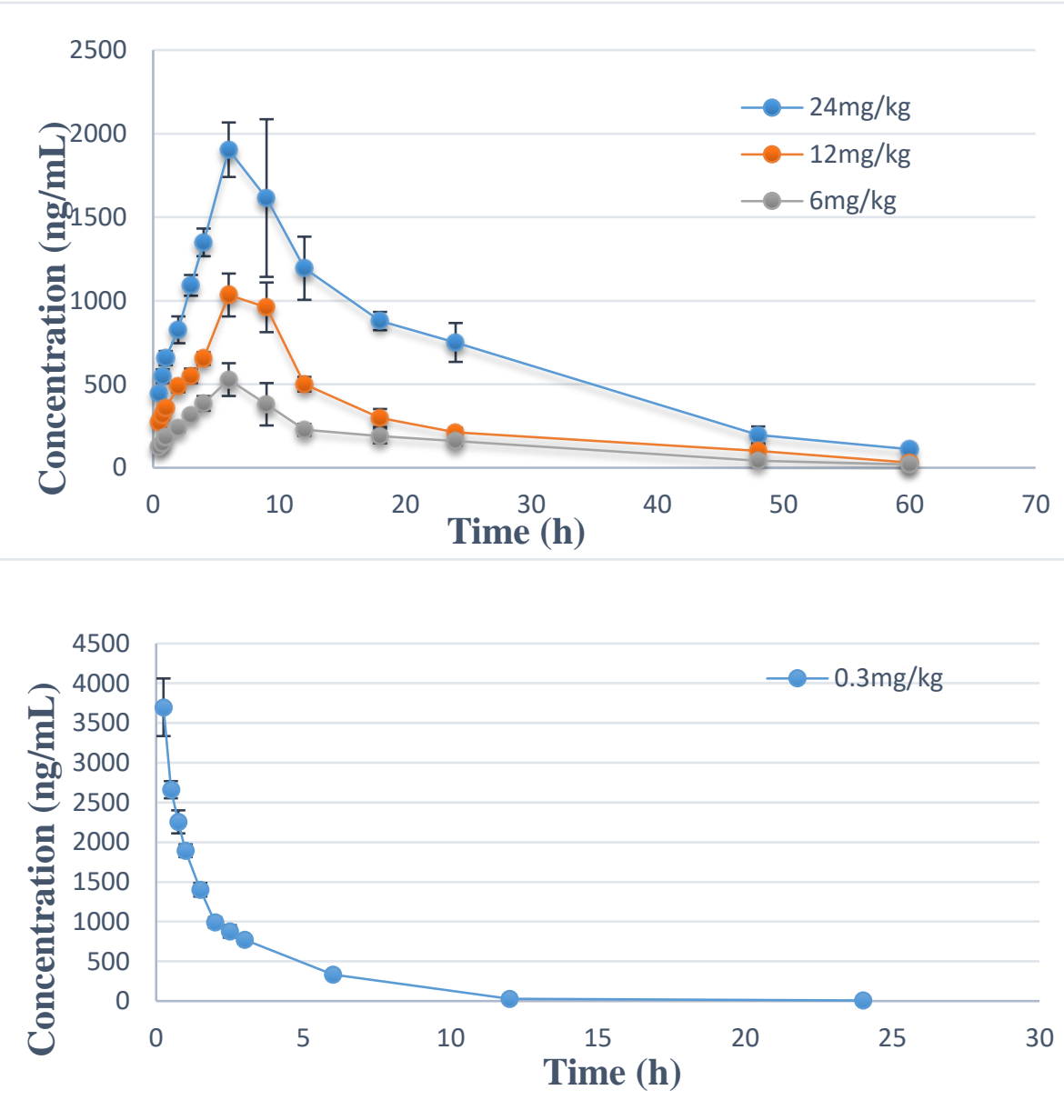

Figure 3. Mean plasma concentration-time profiles of RPDQ after intragastric administration (A) and intravenous administration $(\mathbf{B})$ in rats.

\subsubsection{Results of Metabolites Identification of RPDQ}

To determine the fragmentation patterns, the reference compound of RPDQ was used for the major MS/MS fragments in UPLC-QTOF-MS ${ }^{\mathrm{E}}$. Just as shown in Table 5, RPDQ generated a protonated ion $[\mathrm{M}+\mathrm{H}]^{+}$at $m / z 609.4346$ and a number of fragment ions at $m / z 549.3856,477.3938,459.3833$, 441.3727, 423.3621, 381.3152, 283.2420, and 143.1067. The retention time of RPDQ was $16.64 \mathrm{~min}$ at the UPLC elution, and the molecular ion was $m / z 609.4346$ in mass spectrum.

By using the UPLC-Q/TOF-MS method and being analyzed in parallel with blank control, RPDQ-dosed plasma, bile, urine, and feces samples were analyzed. In spite of lacking standards for the metabolites, the structures of them could be estimated based on retention time and mass spectral patterns between RPDQ and its product ions. According to certain rules, such as mass accuracy $( \pm 5 \mathrm{ppm})$, isotopic pattern, nitrogen rule, and double-bond equivalents, the most possible molecular formulas of metabolites were analyzed. Furthermore, based on the MS/MS fragmentation, the tentative chemical structures were identified and common metabolic pathways were profiled. There were 13 metabolites (including 4 Phase I metabolites and 9 Phase II metabolites were shown in Figure 4) whose structures were elucidated and summarized as follows.

Phase I Metabolites. M1, eluted at $13.09 \mathrm{~min}$, was with the $[\mathrm{M}+\mathrm{H}]^{+}$ion at $m / z 647.4144\left(\mathrm{C}_{37} \mathrm{H}_{58} \mathrm{O}_{9}\right)$, $38 \mathrm{Da}$ higher than that of RPDQ. This suggested that the metabolite was oxidation and acetylation metabolite. According to the characteristic product fragments at $m / z 357.2788, m / z 355.2632$, and $\mathrm{m} / \mathrm{z}$ 439.3570, estimated binding sites at C-3 [24]. 
M2 (RT $=13.10 \mathrm{~min}$ ) showed a protonated ion at $m / z$ 625.4330, suggesting that the molecular formula was $\mathrm{C}_{35} \mathrm{H}_{60} \mathrm{O}_{9}$. This metabolite was 16 Da higher than RPDQ. Compared with $\mathrm{m} / z 477.3938$ and $m / z 441.3727$ from RPDQ, the diagnostic ion $m / z 493.3866$ and $m / z 457.3649$ was 16 Da higher than them. Therefore, M2 was identified as an oxidrolysis metabolite of RPDQ [25].

M6 was eluted at $25.20 \mathrm{~min}$, showed an accurate protonated ion at $m / z 549.4867\left(\mathrm{C}_{35} \mathrm{H}_{64} \mathrm{O}_{4}\right)$, $60 \mathrm{Da}$ less than that of RPDQ. This observation suggested that the metabolite was a reduction and oxidation metabolite. The characteristic fragment ion $(m / z$ 416.4376) signified that reduction and oxidation occurred at the parent nucleus. The other main productions were $m / z 541.3839, m / z 521.3837$, and $m / z$ 477.3575.

M13 was eluted at $28.18 \mathrm{~min}$, with $[\mathrm{M}+\mathrm{H}]^{+}$ion at $m / z 629.4687\left(\mathrm{C}_{35} \mathrm{H}_{64} \mathrm{O}_{9}\right), 20$ Da higher than that of RPDQ. This suggested that it was a reduction and hydration metabolite. It was implied that the reduction and hydration occurred at the parent nucleus [26], according to the characteristic fragment ion $(m / z$ 569.4427).

Phase II Metabolites. M3, eluted at $13.34 \mathrm{~min}$, was with the $[\mathrm{M}+\mathrm{H}]^{+}$ion at $m / z 781.4389$ $\left(\mathrm{C}_{40} \mathrm{H}_{64} \mathrm{O}_{14}\right), 172 \mathrm{Da}$ higher than of RPDQ. This suggested that it was an oxidation and glucuronidation metabolite. The characteristic fragment ion at $m / z 545.3475$ meant that oxidation occurred at the parent nucleus. The characteristic fragment ion at $m / z 723.4678$ and $m / z 315.2296$ signified that glucuronidation occurred at C-20.

M4 was eluted at $13.49 \mathrm{~min}$, with the predominant quasi-molecular ion $[\mathrm{M}+\mathrm{H}]^{+} \mathrm{m} / z 689.3936$ $\left(\mathrm{C}_{35} \mathrm{H}_{60} \mathrm{O}_{11} \mathrm{~S}\right), 80$ Da more than that of RPDQ, which implies that it was a sulfated product of RPDQ. The characteristic fragment ion at $m / z 539.3401$ and $m / z 521.3295$ signified that sulfation occurred at the parent nucleus. Therefore, M4 was identified as the sulfation metabolite of RPDQ [26].

M5 was eluted at $21.39 \mathrm{~min}$, with the $[\mathrm{M}+\mathrm{H}]^{+}$ion at $m / z$ 477.3947, $132 \mathrm{Da}$ (ribose) lower than that of RPDQ. Moreover, the MS fragmentation patterns were similar to the reference substance of PDQ, with the characteristic fragment ion at $m / z$ 441.3727, $m / z$ 283.2420, and $m / z$ 143.1067. Hence, M5 was the aglycone of RPDQ.

M7, the metabolite at $m / z 459.3815\left(\mathrm{C}_{30} \mathrm{H}_{50} \mathrm{O}_{3}\right), 50$ Da less than that of RPDQ, was eluted at $18.06 \mathrm{~min}$. The characteristic ions included $\mathrm{m} / \mathrm{z}$ 457.3675, $\mathrm{m} / \mathrm{z} 441.3727$, and $\mathrm{m} / \mathrm{z}$ 439.3570. The product ions at $m / z 457.3675$ and $m / z 439.3570$ suggested that it was a deglycosylation and hydration metabolite. The characteristic fragment ion at $m / z 441.3727$ and $m / z 143.2011$ signified that deglycosylation occurred at C-12.

The molecular formula of $\mathbf{M 8}$ and $\mathbf{M 1 2}$ were $\mathrm{C}_{40} \mathrm{H}_{72} \mathrm{~N}_{2} \mathrm{O}_{7} \mathrm{~S}$ and $\mathrm{C}_{41} \mathrm{H}_{72} \mathrm{O}_{10}$, respectively, and they were 176 Da higher than that of M6. They were eluted at 25.65 and $27.91 \mathrm{~min}$, showing the ions at $\mathrm{m} / \mathrm{z}$ 725.5117 and $m / z$ 725.5220, respectively. Furthermore, the distinctive fragment ions at $m / z 549.4657$, indicating that M8 was the metabolite of cysgly $S$ adduction. The typical fragment ion at $m / z 143.1254$ and 549.4657 signified that cysgly $S$ adduction occurred at C-3. Distinctive fragment ions at $m / z$ 549.4758 were observed, indicating that M12 was a metabolite of glucosylation. The characteristic fragment ion at $m / z 549.4758$ and 143.1014 signified that glucosylation occurred at C-3 [27].

M9 was eluted at $27.34 \mathrm{~min}$ and showed a predominant quasi-molecular ion $[\mathrm{M}+\mathrm{H}]^{+}$ $m / z 709.4263\left(\mathrm{C}_{35} \mathrm{H}_{65} \mathrm{O}_{12} \mathrm{P}\right), 80 \mathrm{Da}$ more than that of RPDQ, suggesting that it was a reduction, hydration and phosphorylation product of RPDQ. The characteristic fragment ion at $m / z 505.3441$, $m / z 481.3888$, and $m / z 463.3781$ signified that phosphorylation occurred at the parent nucleus. Therefore, M9 was identified as the phosphorylation metabolite of RPDQ [28].

M10, with the molecular formula $\mathrm{C}_{37} \mathrm{H}_{63} \mathrm{NO}_{9}$, which was 57 Da higher than that of RPDQ, were eluted at $27.35 \mathrm{~min}$ and showed the protonated ions at $\mathrm{m} / \mathrm{z}$ 666.4598. The ions at $\mathrm{m} / z$ 495.3754 and $m / z 516.3819$ suggested that the metabolite was glycine conjugation metabolite. The characteristic fragment ion $(m / z 495.3754)$ suggested that glycine conjugation occurred at the parent nucleus $[29,30]$.

M11, $\mathrm{C}_{45} \mathrm{H}_{79} \mathrm{~N}_{3} \mathrm{O}_{9} \mathrm{~S}$, suggesting 289 Da higher than that of M6. It was eluted at $27.65 \mathrm{~min}$ and showed the protonated ions at $m / z$ 838.5641. The product ions at $m / z 549.4627$ and $m / z 718.4459$ 
suggested that the metabolite was glutathione conjugation metabolite. The fragment ion at $\mathrm{m} / \mathrm{z}$ $549.4627, m / z 718.4459$, and $m / z 143.0924$ signified that glutathione conjugation occurred at C-3 [29,30]. In summary, an analytical strategy for fast screening and identification metabolites of RPDQ by using UPLC-Q-TOF-MS ${ }^{\mathrm{E}}$ and UNIFI 1.7.0 software (Waters, Manchester, UK) was explored in this study. According to 13 metabolic pathways, Phase II metabolites were the main metabolic pathway, including glycine conjugation, sulfation, phosphorylation, glucuronidation, glutathione, cysgly $\mathrm{S}$ conjugation, adduction, glucosylation and deglycosylation. Moreover, the Phase I metabolites included oxidation, acetylation, hydration, and reduction reactions. These pathways indicated that the hydroxy of RPDQ was the major metabolic site in vivo. The results provide a theoretical foundation and a better understanding of the biotransformation of RPDQ.

Table 5. Metabolites of RPDQ characterized by using UPLC-Q-TOF-MS ${ }^{\mathrm{E}}$.

\begin{tabular}{|c|c|c|c|c|c|c|c|c|}
\hline No. & $\begin{array}{c}\mathrm{RT} \\
(\mathrm{min})\end{array}$ & Formula & $\begin{array}{c}\text { Measured } \\
\text { Mass }(\mathrm{m} / \mathrm{z})\end{array}$ & $\begin{array}{l}\text { Calculate } \\
\text { Mass }(\mathrm{m} / \mathrm{z})\end{array}$ & $\begin{array}{c}\text { Error } \\
(\mathrm{ppm})\end{array}$ & Fragment Ions & $\begin{array}{l}\text { Metabolic } \\
\text { Pathway }\end{array}$ & Source \\
\hline RPDQ & 16.65 & $\mathrm{C}_{35} \mathrm{H}_{60} \mathrm{O}_{8}$ & 609.4346 & 609.8540 & 1.3 & $\begin{array}{c}549.3856,477.3938 \\
459.3833,441.3727 \\
381.3152,283.2420 \\
143.1067\end{array}$ & parent & $\begin{array}{l}\mathrm{P}, \mathrm{B} \\
\mathrm{F}, \mathrm{U}\end{array}$ \\
\hline M1 & 13.09 & $\mathrm{C}_{37} \mathrm{H}_{58} \mathrm{O}_{9}$ & 647.4144 & 647.8590 & -1.4 & $\begin{array}{c}475.3782,457.3675 \\
439.3569,421.3464 \\
357.2788,355.2632 \\
143.1067\end{array}$ & $\begin{array}{l}\text { Desaturation } \\
\text { Acetylation }\end{array}$ & $\mathrm{F}$ \\
\hline M2 & 13.10 & $\mathrm{C}_{35} \mathrm{H}_{60} \mathrm{O}_{9}$ & 625.4330 & 625.8534 & 3.3 & $\begin{array}{c}493.3866,457.3649 \\
475.3781,439.3565 \\
143.1024\end{array}$ & Oxidation & $\mathrm{F}, \mathrm{U}$ \\
\hline M3 & 13.34 & $\mathrm{C}_{41} \mathrm{H}_{64} \mathrm{O}_{14}$ & 781.4389 & 781.9464 & 2.7 & $\begin{array}{l}723.4678,573.4149 \\
545.3472,315.2318\end{array}$ & $\begin{array}{c}\text { Desaturation } \\
\text { Glucuronidation }\end{array}$ & $\mathrm{U}$ \\
\hline M4 & 13.49 & $\mathrm{C}_{35} \mathrm{H}_{60} \mathrm{O}_{11} \mathrm{~S}$ & 689.3936 & 689.9172 & 1.1 & $\begin{array}{c}675.3792,670.3783 \\
539.3401,521.3295 \\
503.3189,441.3708 \\
143.1067\end{array}$ & Sulfation & $\mathrm{F}$ \\
\hline M5 & 21.39 & $\mathrm{C}_{30} \mathrm{H}_{52} \mathrm{O}_{4}$ & 477.3932 & 477.7394 & 1.4 & $\begin{array}{l}459.3832,441.3727 \\
423.3621,381.3152 \\
283.2420,143.1067\end{array}$ & Deglycosylation & $\begin{array}{l}\mathrm{P}, \mathrm{B} \\
\mathrm{F}, \mathrm{U}\end{array}$ \\
\hline M6 & 25.20 & $\mathrm{C}_{35} \mathrm{H}_{64} \mathrm{O}_{4}$ & 549.4867 & 549.8882 & -1.8 & $\begin{array}{c}541.3839,521.3837 \\
477.3575,416.4376 \\
283.2457\end{array}$ & Nitor reduction & $\mathrm{F}, \mathrm{U}$ \\
\hline M7 & 18.06 & $\mathrm{C}_{30} \mathrm{H}_{50} \mathrm{O}_{3}$ & 459.3815 & 459.7241 & 4.7 & $\begin{array}{c}457.3675,441.3727 \\
439.3570,421.3465 \\
45.3515,381.3117 \\
143.1067\end{array}$ & $\begin{array}{l}\text { Desaturation } \\
\text { Hydration }\end{array}$ & $\begin{array}{l}\mathrm{P}, \mathrm{B} \\
\mathrm{F}, \mathrm{U}\end{array}$ \\
\hline M8 & 25.65 & $\mathrm{C}_{40} \mathrm{H}_{72} \mathrm{~N}_{2} \mathrm{O}_{7} \mathrm{~S}$ & 725.5117 & 726.0818 & -2.2 & $\begin{array}{l}715.4351,557.4126 \\
465.3574, \\
340.3538,143.1254\end{array}$ & $\begin{array}{l}\text { CysGly S } \\
\text { adduction }\end{array}$ & $\mathrm{P}, \mathrm{F}$ \\
\hline M9 & 27.34 & $\mathrm{C}_{35} \mathrm{H}_{65} \mathrm{O}_{12} \mathrm{P}$ & 709.4263 & 709.8651 & 1.9 & $\begin{array}{l}505.3441,495.4044 \\
481.3888,463.3781\end{array}$ & Phosphorylation & $\mathrm{P}, \mathrm{F}, \mathrm{U}$ \\
\hline M10 & 27.35 & $\mathrm{C}_{37} \mathrm{H}_{63} \mathrm{NO}_{9}$ & 666.4598 & 666.9054 & 3.2 & $\begin{array}{c}551.39423 \\
534.4177,516.3819 \\
495.3707,143.1052\end{array}$ & $\begin{array}{c}\text { Glycine } \\
\text { conjugation }\end{array}$ & $\mathrm{P}, \mathrm{B}$ \\
\hline M11 & 27.65 & $\mathrm{C}_{45} \mathrm{H}_{79} \mathrm{~N}_{3} \mathrm{O}_{9} \mathrm{~S}$ & 838.5641 & 839.1964 & 3.8 & $\begin{array}{c}\text { 718.4459, 549.4627, } \\
520.3758 \\
513.35745 \\
270.3118,143.0924\end{array}$ & $\begin{array}{l}\text { Glutathione } \\
\text { conjugation }\end{array}$ & $\begin{array}{l}\mathrm{P}, \mathrm{B} \\
\mathrm{F}, \mathrm{U}\end{array}$ \\
\hline M12 & 27.91 & $\mathrm{C}_{41} \mathrm{H}_{72} \mathrm{O}_{10}$ & 725.5152 & 725.0123 & 3.1 & $\begin{array}{l}557.3817,549.4758 \\
443.3841,143.1014\end{array}$ & Glucosylation & $\begin{array}{l}\mathrm{P}, \mathrm{B} \\
\mathrm{F}, \mathrm{U}\end{array}$ \\
\hline M13 & 28.18 & $\mathrm{C}_{35} \mathrm{H}_{64} \mathrm{O}_{9}$ & 629.4687 & 629.8852 & 1.0 & $\begin{array}{c}594.4491,569.4427 \\
461.3625,303.3046 \\
143.2017\end{array}$ & $\begin{array}{l}\text { Reduction } \\
\text { Hydration }\end{array}$ & B \\
\hline
\end{tabular}




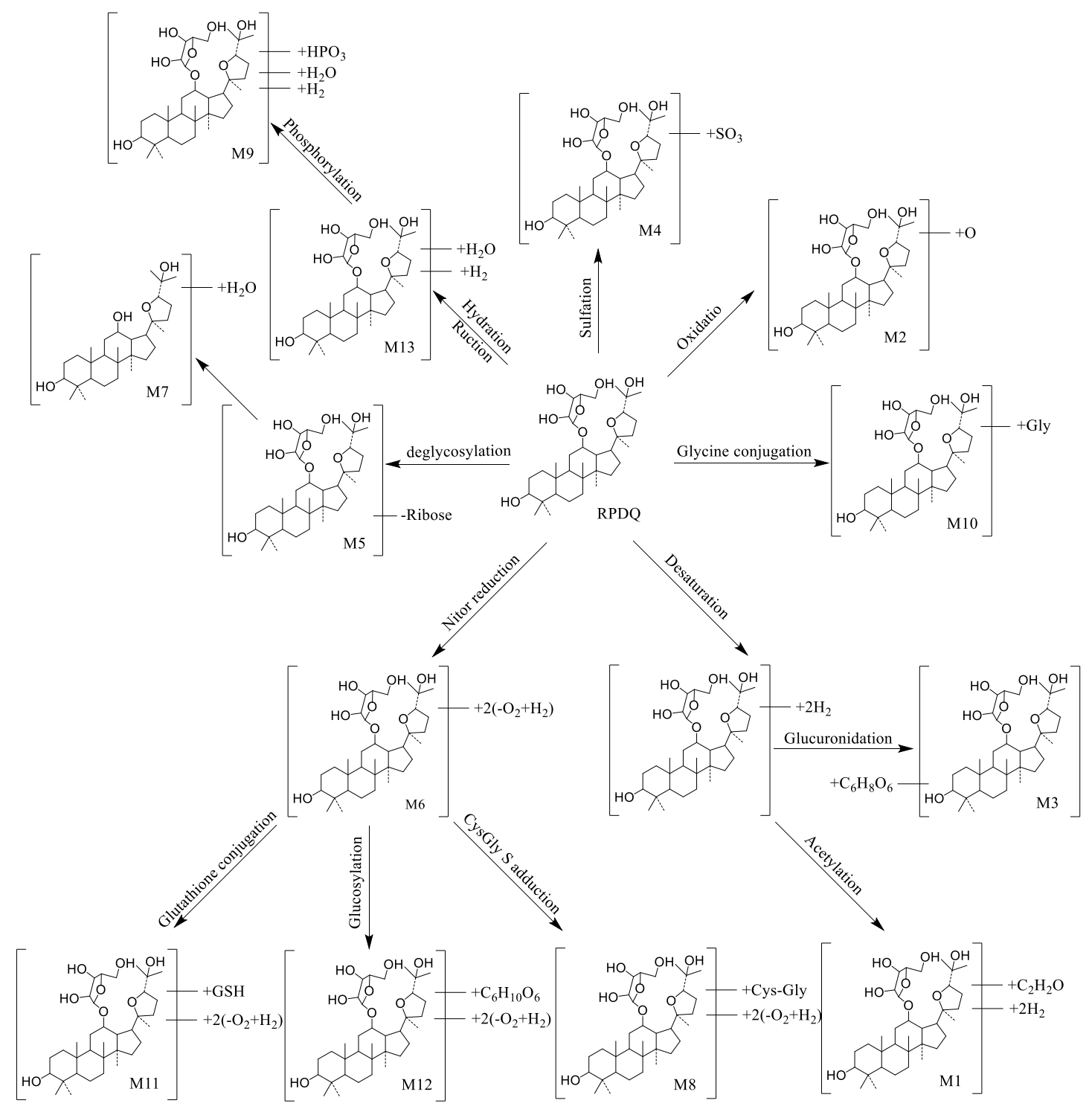

Figure 4. The proposed metabolic pathways of RPDQ in rats.

\section{Discussion}

Aiming at discussing the characteristics of the ginsenoside with glycosylation site at C-12, the pharmacokinetic and metabolism studies of RPDQ were carried out. Firstly, a UPLC-MS/MS method, with a short running time $(3.5 \mathrm{~min})$ and a high sensitivity $(5 \mathrm{ng} / \mathrm{mL})$, was validated and developed for the pharmacokinetic study. Secondly, pharmacokinetic analysis suggested that RPDQ was slowly absorbed, slowly eliminated, and had poor bioavailability in rats. Compared with other ginsenosides $\left(\mathrm{Rh}_{1}, \mathrm{Rh}_{2}\right.$, and $\left.\mathrm{CK}\right)$ also containing one glycosyl group, the elimination half-life $\left(t_{1 / 2}\right)$ takes much longer time and the bioavailability was higher than them. Meanwhile, compared with ginsenosides $\left(\mathrm{Rb}_{1}, \mathrm{Rb}_{2}\right.$, and $\left.\mathrm{Rb}_{3}\right)$ containing two or more polysaccharide groups, the elimination half-life $\left(t_{1 / 2}\right)$ was lower, but the bioavailability was higher. On the other hand, compared with 3-position, 6-position, and 20-position glycosyl ginsenosides $\left(\mathrm{Rh}_{1}, \mathrm{Rh}_{2}, \mathrm{Rg}_{2}, \mathrm{Rg}_{3}\right.$, and $\left.\mathrm{CK}\right)$, the elimination half-life of RPDQ was much longer than $\mathrm{Rh}_{2}$ and $\mathrm{Rg}_{3}$. The bioavailability of RPDQ was also better than them all [31-33]. Compared with sapogenin (PPD, PPT, and PDQ), the elimination half-life of RPDQ longer than them. However, the bioavailability of PPD and PDQ was much higher than that of RPDQ. Finally, the main metabolites were characterized, and the proposed metabolic pathways of RPDQ were also profiled. The findings suggest that Phase II reactions are the principal 
metabolic pathway of RPDQ in vivo. Meanwhile, metabolite identification results proved that RPDQ mainly underwent some metabolism in the liver, since all metabolites could been found in the bile, urine, and feces samples. Taking the results obtained in this study into consideration, we concluded that the hepatic microsome might be the major cause for the poor oral bioavailability of RPDQ in rats. Moreover, RPDQ was also detected in plasma, urine, bile, and feces samples, which explains why RPDQ had a slow clearance rate in rats. In addition, except common metabolisms such as oxidation, glucuronidation, and deglycosylation, glutathione conjugation was found due to the epoxidized groups linked at C-20.

\section{Materials and Methods}

\subsection{Chemicals and Ragents}

RPDQ, internal standard (IS, 20R-panaxadiol), and standard substance of M5 (pseudoginsengenin DQ) with a purity of more than $98 \%$ were provided by the School of Pharmaceutical Sciences of Jilin University (Changchun, China). Their structures were confirmed using HR-MS and ${ }^{1} \mathrm{H}$ and ${ }^{13} \mathrm{C}$-nuclear magnetic resonance (NMR) spectroscopy. The chemical structures of RPDQ and 20R-panaxadiol are shown in Figure 5. Acetonitrile and methanol used in the study were all UPLC-MS pure grade (Fisher Chemical Company, Geel, Belgium). Other chemicals were of analytical grade. Deionized water was purified using a Millipore water purification system (Millipore, Billerica, MA, USA). Formic acid was purchased from the Company of Sigma-Aldrich. Blank rat plasma used was prepared by our group.

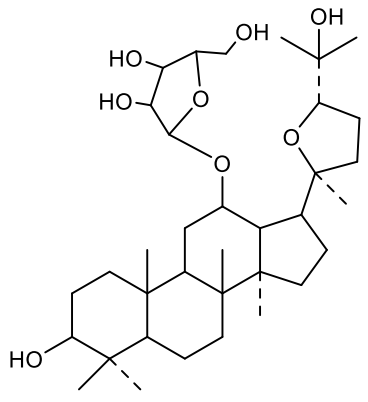

RPDO

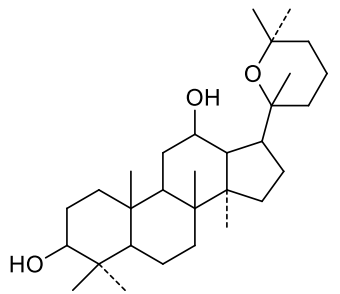

20R-

Figure 5. Chemical structures of 12-riboside-pseudoginsengenin DQ (RPDQ) and 20R-panaxadiol.

\subsection{Animals and Drug Administration}

The experiments on animals were approved by the Review Committee of Animal Care and Use of Jilin University. The study was conducted according to the ethical principles for animal use and care. Wistar rats $(200 \pm 20 \mathrm{~g})$ were provided by Changchun Yisi Laboratory Animal Co. Ltd. (Changchun, China). All rats were housed in an environmentally controlled room (12 h light/dark cycle; temperature: $22 \pm 2{ }^{\circ} \mathrm{C}$; relative humidity: $55 \pm 5 \%$ ), and except during fast before experiments, the rats were fed with standard laboratory food and water ad libitum.

In the pharmacokinetic study, the rats were divided into different groups $(n=6$, three males and three females): (1) RPDQ (6 mg/ kg, i.g.), (2) RPDQ (12 mg/kg, i.g.), (3) RPDQ (24 mg/kg, i.g.), and (4) RPDQ (0.3 mg/ $\mathrm{kg}$, i.v. $)$.

For a metabolism study, RPDQ (48 mg/ $\mathrm{kg}$, i.g.) was administered to obtain a high concentration of metabolites. 


\subsection{Sample Preparation}

\subsubsection{Pharmacokinetic Study}

RPDQ and 20R-panaxadiol stock methanol solutions $(1.00 \mathrm{mg} / \mathrm{mL})$ were all prepared with the reference compounds, respectively. Firstly, blank rat plasma was prepared. The blood samples were collected immediately from the abdominal aorta and incubated at $37{ }^{\circ} \mathrm{C}$ for $30 \mathrm{~min}$. The plasma was separated by centrifugation at $4000 \mathrm{rpm}$ for $15 \mathrm{~min}$, and was frozen at $-20{ }^{\circ} \mathrm{C}$ until analysis. By spiking the dilute solutions with blank rat plasma, calibration curves were plotted to produce the points equivalent to 5, 10, 25, 50, 100,300,500, and $1000 \mathrm{ng} / \mathrm{mL}$ for RPDQ. With the same method as calibration standards, 15,200 , and $800 \mathrm{ng} / \mathrm{mL}$ of quality control (QC) samples were independently prepared. All the QC and calibration standards samples were prepared freshly before analysis.

From the fossa orbitalis vein, the whole blood $(150 \mu \mathrm{L})$ was collected at $0.5,0.75,1,2,3,4,6,9$, $10,12,18,24,48$, and $60 \mathrm{~h}$ after oral administration, and $0.25,0.5,0.75,1,1.5,2,2.5,3,6,12$, and $24 \mathrm{~h}$ after intravenous administration. All the blood samples were anticoagulated with sodium heparin. After collection, the whole blood was centrifuged at $4000 \mathrm{rpm}$ and $4{ }^{\circ} \mathrm{C}$ for $20 \mathrm{~min}$ to obtain plasma.

Plasma samples (being stored at $-20{ }^{\circ} \mathrm{C}$ before analysis) were thawed and vortexed at room temperature. The mixture of each plasma sample $(50 \mu \mathrm{L})$ and $20 R$-panaxadiol solution $(100 \mathrm{ng} / \mathrm{mL}$, $500 \mu \mathrm{L})$ was vortexed $(2 \mathrm{~min})$ and centrifuged $\left(13,000 \mathrm{rpm}, 4{ }^{\circ} \mathrm{C}, 10 \mathrm{~min}\right)$. The clear supernatant was obtained and transferred into vials, and $2 \mu \mathrm{L}$ of it were then kept in autosampler at $4{ }^{\circ} \mathrm{C}$ and injected for analysis.

\subsubsection{Metabolism Study}

Blood samples were collected at $0.25,0.5,0.75,1,1.5,2,2.5,3,6,12$, and $24 \mathrm{~h}$ after intragastric administration. The pooled plasma sample $(500 \mu \mathrm{L})$ was then added with methanol $(2 \mathrm{~mL})$ to vortex and precipitate proteins. Subsequently, the mixtures were centrifuged $\left(10,000 \mathrm{rpm}, 4{ }^{\circ} \mathrm{C}, 10 \mathrm{~min}\right)$ to obtain the supernatant, which was then evaporated by $\mathrm{N}_{2}$ to obtain the residue. Methanol $(100 \mu \mathrm{L})$ was used to reconstitute the residue.

In order to obtain bile samples, rats were anaesthetized with urethane $(1.0 \mathrm{~g} / \mathrm{kg}$, intraperitoneal injection). After making an abdominal incision, the bile was collecting by surgically inserting a plastic cannula into the bile ducts. Prior to administration, blank bile was collected for $2 \mathrm{~h}$. After administration, bile samples were collected for $12 \mathrm{~h}$.

By using metabolism cages, blank and dosed urine and feces samples were also collected prior to administration or $24 \mathrm{~h}$ after administration. After diluting each urine or bile sample $(300 \mu \mathrm{L}) \mathrm{with}$ $1 \mathrm{~mL}$ of methanol, the mixture was centrifuged $\left(10,000 \mathrm{rpm}, 4{ }^{\circ} \mathrm{C}, 10 \mathrm{~min}\right)$ to obtain the supernatant, which was then evaporated by $\mathrm{N}_{2}$ to obtain the dried urine or bile residue. Methanol $(50 \mu \mathrm{L})$ was then used to dissolve each residue. After centrifuging $\left(10,000 \mathrm{rpm}, 4^{\circ} \mathrm{C}, 10 \mathrm{~min}\right)$, the clear supernatants were used for the analysis.

Each sample of dried feces powder $(10 \mathrm{mg})$ was extracted with methanol $(1 \mathrm{~mL})$ by being ultrasonicated for $30 \mathrm{~min}$ in an ice-water bath. The mixture was then centrifuged $\left(10,000 \mathrm{rpm}, 4^{\circ} \mathrm{C}\right.$, $10 \mathrm{~min}$ ) to obtain the clear supernatant. Similarly, the supernatant was evaporated to obtain the dried residue, which was supplemented with $500 \mu \mathrm{L}$ of methanol to be reconstituted and centrifuged at $10,000 \mathrm{rpm}$ for $10 \mathrm{~min}$ at $4{ }^{\circ} \mathrm{C}$. Additionally, all biological samples were stored at $-20{ }^{\circ} \mathrm{C}$.

\subsection{Instruments and Experimental Conditions}

\subsubsection{LC-MS/MS Conditions}

The analysis of pharmacokinetic was conducted on a Waters ACQUITY UPLC System coupled with a XEVO TQ-S mass spectrometer equipped with an electrospray ionization source (Waters, Milford, MA, USA). Separation was performed on a Waters BEH C18 UPLC column $(2.1 \times 50 \mathrm{~mm}, 1.7 \mu \mathrm{m})$ at $40{ }^{\circ} \mathrm{C}$. The mobile phase, $0.1 \%$ formic aqueous solution (A) and $0.1 \%$ formic acid in acetonitrile (B) in 
proportions, was adjusted with a gradient elution programme (0 min, 40\% B; 0 2 $\mathrm{min}, 40 \sim 100 \% \mathrm{~B}$; 2 2.5 min, 100\% B; 2.5 2.6 min, 100 40\% B; 2.6 3.5 min, 100\% B). The flow rate was kept constant at $0.3 \mathrm{~mL} / \mathrm{min}$. Chromatography of the RPDQ and IS was performed within $3.5 \mathrm{~min}$. The injection volume was $2 \mu \mathrm{L}$. The multiple reaction monitoring (MRM) mode was performed in $\mathrm{ESI}^{+}$. The main parameters were as follows: capillary voltage: $3000 \mathrm{~V}$; source temperature: $150{ }^{\circ} \mathrm{C}$; desolvation temperature: $300{ }^{\circ} \mathrm{C}$; desolvation gas flow: $800 \mathrm{~L} / \mathrm{h}$; cone gas flow: $150 \mathrm{~L} / \mathrm{h}$; nebulizer gas flow: 7 bar; collision gas flow: $0.15 \mathrm{~mL} / \mathrm{min}$; cone voltage: $35 \mathrm{~V}$ and $28 \mathrm{~V}$ for RPDQ and IS, respectively; collision energy: $10 \mathrm{eV}$ and $6 \mathrm{eV}$ for RPDQ and IS, respectively. Masslynx V4.1 workstation (Waters, Milford, MA, USA) was used for data acquisition and processing [34-38].

\subsubsection{UPLC-QTOF/MS Conditions}

A Waters ACQUITY UPLC System coupled with a Xevo G2-S Q-TOF mass spectrometer (Waters, USA) was used to profile the metabolites. An ESI source in the positive ionization mode was equipped. A Waters UPLC BEH $C_{18}$ column $(2.1 \times 50 \mathrm{~mm}, 1.7 \mu \mathrm{m})$ was used with a column temperature at $30{ }^{\circ} \mathrm{C}$ and a flow rate at $0.4 \mathrm{~mL} / \mathrm{min}$. The autosampler temperature was set at $4{ }^{\circ} \mathrm{C}$ and the injection volume was $10 \mu \mathrm{L}$. The mobile phase was composed of $0.1 \%$ formic aqueous solution (A) and $0.1 \%$ formic acid in acetonitrile (B). The gradient elution programme was as follows: 0 2 min, $10 \% \mathrm{~B} ; 2 \sim 26 \mathrm{~min}, 10 \rightarrow 100 \% \mathrm{~B} ; 26 \sim 28 \mathrm{~min}, 100 \% \mathrm{~B} ; 28 \sim 28.1 \mathrm{~min}, 100 \rightarrow 10 \% \mathrm{~B}, 28.1 \sim 30 \mathrm{~min}, 10 \% \mathrm{~B}$. The following optimized conditions were employed: capillary voltage: $2.6 \mathrm{kV}$; cone voltage: $40 \mathrm{~V}$; desolvation temperature: $300{ }^{\circ} \mathrm{C}$; source temperature: $120^{\circ} \mathrm{C}$; cone gas flow: $50 \mathrm{~L} / \mathrm{h}$; desolvation gas flow: $800 \mathrm{~L} / \mathrm{h}$. The energy of low energy function and the collision energy of high energy function was set at $6 \mathrm{~V}$ and $20 \sim 40 \mathrm{~V}$, respectively, in $\mathrm{MS}^{\mathrm{E}}$ mode. The mass spectrometer was calibrated with sodium formate in a range of 100-1600 Da. Leucine-enkephalin $(m / z 556.2771)$ was used as the lockmass at a flow rate of $10 \mu \mathrm{L} / \mathrm{min}$ and a concentration of $200 \mathrm{ng} / \mathrm{mL}$. Data were collected by Masslynx V4.1 workstation in continuum mode. Metabolic characterization of RPDQ was analyzed using UNIFI 1.7.0 software (Waters, Manchester, UK) [39].

\subsection{Method Validation}

The specificity, linearity, LLOQ, precision and accuracy, extraction recovery, matrix effect, diluted reliability, and stability of the method were validated by following a non-clinical drug pharmacokinetic study technical guideline (China Food And Drug Administration 2014) and the Bioanalytical Method Validation Guideline (Chinese Pharmacopoeia 2015, Vol. 4). Specificity was assessed by comparing blank plasma samples, plasma was spiked with RPDQ and 20R-panaxadiol, and plasma samples were collected after administration. Linearity was analyzed through weighted regression $\left(1 / x^{2}\right)$ of peak area ratios $(y)$ of RPDQ to 20R-panaxadiol versus nominal concentration $(x)$ in plasma. LLOQ was the lowest concentration on the calibration curve, with acceptable precision (RSD $\leq 20 \%$ ) and accuracy $(\mathrm{RE} \leq \pm 20 \%$ ), while precision and accuracy were assessed with QC samples $(15,200$, and $800 \mathrm{ng} / \mathrm{mL})$. The intra- and inter-day precision and accuracy were evaluated with the analysis of six replicate QC samples on three consecutive days, respectively. The extraction recovery and matrix effect at three QC concentrations were assayed. By comparing peak areas of RPDQ and 20R-panaxadiol in extracted QC samples with those in post-extracted blank plasma samples, the recoveries were calculated. Moreover, by comparing the peak area of samples spiked after extraction with that of the neat solution's equivalent concentration, the matrix effect was then evaluated. Stability was evaluated by analyzing replicate QC samples, which were stored at $-20^{\circ} \mathrm{C}$ for two weeks at room temperature for $4 \mathrm{~h}$, and experienced three freeze/thaw cycles (from $-20^{\circ} \mathrm{C}$ to room temperature) on consecutive days. The stabilities of RPDQ in stock solutions at $15^{\circ} \mathrm{C}$ and stored in plastic autosampler vials for $16 \mathrm{~h}$ at $10^{\circ} \mathrm{C}$ were also assessed. Five-fold higher concentrations of QC were achieved by adding moderate RPDQ to blank plasma. The samples were then diluted and analyzed with undiluted calibration standards. The accuracy and precision were within acceptable limits $( \pm 15 \%)$. 


\subsection{Pharmacokinetic Study}

Samples containing RPDQ above the upper limit of quantification were diluted and re-analyzed. The pharmacokinetics analysis in non-compartmental mode was conducted by Drug and Statistics (DAS) 3.0 pharmacokinetic software programme (Mathematical Pharmacology Professional Committee of China, Shanghai, China). The concentration versus the time curve was plotted. The time to reach the peak concentration $\left(T_{\max }\right)$ and the maximum plasma concentration $\left(C_{\max }\right)$ were obtained after oral administration. The results are shown as the mean \pm standard deviation. The absolute bioavailability $(F \%)$ was calculated using the equation (AUCp.o. $\times$ Dosei.v. $) /($ AUCi.v. $\times$ Dosep.o. $) \times 100 \%$.

\section{Conclusions}

In this study, the pharmacokinetic and metabolism studies of 12-riboside-pseudoginsengenin DQ (RPDQ) were performed for the first time in this study. In pharmacokinetic analysis, a UPLC-MS/MS method for quantification was developed and validated. The method was then successfully applied to the pharmacokinetic study after intravenous administration of $0.3 \mathrm{mg} / \mathrm{kg}$ RPDQ and intragastric administration of 6,12 , and $24 \mathrm{mg} / \mathrm{kg}$ RPDQ. The results showed that RPDQ exhibited slow oral absorption $\left(T_{\max }=7.5 \mathrm{~h}\right)$, low elimination $\left(t_{1 / 2}=12.83 \mathrm{~h}\right)$, and poor absolute bioavailability $(F=5.15 \%)$. A metabolic investigation of RPDQ was carried out through UPLC-QTOF-MS ${ }^{\mathrm{E}}$. The main metabolites and metabolic pathways were all characterized. Overall, compared with the ginsenosides with C-3, C-6, and C-20 glycoside positions, RPDQ has special pharmacokinetic parameters and metabolic pathways. These findings could provide data and reference for further research and applications of RPDQ.

Supplementary Materials: The following are available online at http:/ / www.mdpi.com/1420-3049/23/10/2499/ s1: Structural determination of PPDQ. s2: Antitumor activity test of RPDQ in vitro by using S180, SPC-A-1 and A549 cells. s3: The representative spectra for the metabolites identification.

Author Contributions: Experimental design: J.L. and P.L.; experimental operation: Z.W., B.Z., H.L., and Z.H.; data analysis: Z.W, N.Y., and C.W.; writing—original draft: Z.W; writing—review \& editing: J.L. and P.L.

Funding: This research was supported by the Science and Technology Development Plan of Jilin Province, No: 201603033YY.

Conflicts of Interest: There is no conflict of interest concerning this article.

\section{References}

1. Peng, D.; Wang, H.; Qu, C.; Xie, L.; Wicks, S.M.; Xie, J. Ginsenoside Re: Its chemistry, metabolism and pharmacokinetics. Chin. Med. 2012, 7, 2. [CrossRef] [PubMed]

2. Kim, H.K. Pharmacokinetics of ginsenoside $\mathrm{Rb} 1$ and its metabolite compound $\mathrm{K}$ after oral administration of Korean Red Ginseng extract. J. Ginseng Res. 2013, 37, 451-456. [CrossRef] [PubMed]

3. Yang, Z.; Wang, R.; Niu, T.; Gao, S.; Yin, T.; You, M.; Jiang, Z.; Hu, M. Inhibition of P-glycoprotein leads to improved oral bioavailability of compound $\mathrm{K}$, an anticancer metabolite of red ginseng extract produced by gut microflora. Drug Metab. Dispos. Biol. Fate Chem. 2012, 40, 1538-1544. [CrossRef] [PubMed]

4. Wang, S.; Lin, Y.; Li, H. The identification of molecular target of (20S) ginsenoside Rh2 for its anti-cancer activity. Sci. Rep. 2017, 7, 12408. [CrossRef] [PubMed]

5. Wang, W.; Shao, Y.; Ma, S.; Wu, X.; Meng, Q. Determination of 20(S)-protopanaxadiol ocotillol type epimers in rat plasma by liquid chromatography tandem mass spectrometry. J. Chromatogr. B 2012, 887-888, 19-24. [CrossRef] [PubMed]

6. Nguyen, T.T.; Matsumoto, K.; Yamasaki, K.; Watanabe, H. Majonoside-R2 reverses social isolation stress-induced decrease in pentobarbital sleep in mice: Possible involvement of neuroactive steroids. Life Sci. 1997, 61, 395-402. [PubMed]

7. Lee, S.Y.; Jeong, J.J.; Le, T.H.V.; Eun, S.H.; Nguyen, M.D.; Park, J.H.; Kim, D.H. Ocotillol, a Majonoside R2 metabolite, ameliorates 2,4,6-trinitrobenzenesulfonic acidinduced colitis in mice by restoring the balance of Th17/Treg cells. J. Agric. Food Chem. 2015, 63, 7024-7031. [CrossRef] [PubMed] 
8. Zhou, Z.W.; Ma, C.; Zhang, H.Y.; Bi, Y.; Chen, X.; Tian, H.; Xie, X.X.; Meng, Q.G.; Lewis, P.J.; Xu, J.Y. Synthesis and biological evaluation of novel ocotillol-type triterpenoid derivatives as antibacterial agents. Eur. J. Med. Chem. 2013, 68, 444-453. [CrossRef] [PubMed]

9. Tran, Q.L. Triterpene saponins from Vietnamese ginseng (Panax vietnamensis) and their hepatocytoprotective activity. J. Nat. Prod. 2001, 64, 456-461. [CrossRef] [PubMed]

10. Li, X.G.; Zhang, L.X.; Meng, X.Y.; Hou, J.R.; Zhang, J. Isolation, identification and content determination of pseudoginsenoside F11 in American ginseng. J. Jilin Agric. Univ. 2006, 6, 645-648.

11. Toshinobu, M.; Ryoji, K.; Osamu, T.; Zhou, J.; Yang, T.R.; Junzo, S. Saponins of zutziseng, rhizomes of panax japonicus C.A. Meyer var. major (Burk.) C.Y. Wu et K.M. Feng, collected in Yunnan, China. Chem. Pharm. Bull. 1982, 30, 4341-4346.

12. Zou, K.; Zhu, S.; Chihiro, T.; Cai, S.Q.; Katsuko, K. Dammarane-type riterpene saponins from panax japonicus. J. Nat. Prod. 2002, 65, 346-451. [CrossRef] [PubMed]

13. Atopkina, L.N.; Shentsova, E.B.; Anisimov, M.M.; Uvarova, N.I. Structural-functional properties of glycosides from Panax ginseng C. A. Mey. and their analogues. II. Haemolytic activity of keto-derivatives of 20(S)-protopanaxadiol and their glycosides. Rastit. Resur. 2000, 36, 89-95.

14. Bi, Y.; Wang, T.; Meng, Q.; Zhang, J.; Wang, L.; Li, Q.; Zhao, F.; Sun, H. Synthesis and Myocardial Ischemia Protective Effect of Ocotillol-Type Derivatives. Rec. Nat. Prod. 2012, 6, 242-254.

15. Shen, R.; Cao, X.; Laval, S.; Yu, B. Synthesis of Ocotillol-Type Ginsenosides. J. Org. Chem. 2016, 81, 10279-10294. [CrossRef] [PubMed]

16. Nakamura, S.; Sugimoto, S.; Matsuda, H.; Yoshikawa, M. Medicinal flowers. XVII. New dammarane-type triterpene glycosides from flower buds of American ginseng, Panax quinquefolium L. Chem. Pharm. Bull. 2007, 55, 1342-1348. [CrossRef] [PubMed]

17. Ren, H.; Sun, J.; Wang, G.; Xie, H.; Zha, W.; Yan, B.; Sun, F.; Hao, H.; Gu, S.; Sheng, L.; et al. Sensitive determination of 20(S)-protopanaxadiol in rat plasma using HPLC-APCI-MS: Application of pharmacokinetic study in rats. J. Pharm. Biomed. Anal. 2008, 48, 1476-1480. [CrossRef] [PubMed]

18. Gao, H.; Li, Z.; Li, P.; Lin, M.; Han, L.; Wang, F.; Liu, J. Determination of Pseudoginsengenin DQ in rat plasma by UPLC-MS/MS and application of the method in a pharmacokinetic study. J. Chromatogr. B 2013, 933, 1-7. [CrossRef] [PubMed]

19. Zhao, J.; Su, C.; Yang, C.; Liu, M.; Tang, L.; Su, W.; Liu, Z. Determination of ginsenosides Rb1, Rb2, and Rb3 in rat plasma by a rapid and sensitive liquid chromatography tandem mass spectrometry method: Application in a pharmacokinetic study. J. Pharm. Biomed. Anal. 2012, 64-65, 94-97. [CrossRef] [PubMed]

20. Paek, I.B.; Moon, Y.; Kim, J.; Ji, H.Y.; Kim, S.A.; Sohn, D.H.; Kim, J.B.; Lee, S.H. Pharmacokinetics of a ginseng saponin metabolite compound K in rats. Biopharm. Drug Dispos. 2010, 27, 39-45. [CrossRef] [PubMed]

21. Sun, J.; Wang, G.; Haitang, X.; Li, H.; Pan, G.; Ian, T. Simultaneous rapid quantification of ginsenoside Rg1 and its secondary glycoside Rh1 and aglycone protopanaxatriol in rat plasma by liquid chromatography-mass spectrometry after solid-phase extraction. J. Pharm. Biomed. Anal. 2005, 38, 126-132. [CrossRef] [PubMed]

22. Lai, L.; Liu, Y.; Hao, H.; Wang, G.; Chen, X.; Ren, H. Determination of 20(S)-ginsenoside Rh1 and its aglycone 20(S)-protopanaxatriol in rat plasma by sensitive LC-APCI-MS method and its application to pharmacokinetic study. Eur. J. Mass Spectrom. 2009, 15, 57-65. [CrossRef] [PubMed]

23. Lai, L.; Hao, H.; Liu, Y.; Zheng, C.; Wang, Q.; Wang, G.; Chen, X. Characterization of pharmacokinetic profiles and metabolic pathways of 20(S)-ginsenoside Rh1 in vivo and in vitro. Planta Med. 2009, 75, 797-802. [CrossRef] [PubMed]

24. Jing, H.; Chen, H.; Li, C.; Liu, W.; Ma, W.; Rui, W. Screening and Identification of the Metabolites of Water Extracts of Raw and Honey-Processed Astragalus, in Rat Urine Based on UHPLC/ESI-Q-TOF-MS and Multivariate Statistical Analysis. J. Am. Soc. Mass Spectrom. 2018, 29, 1919-1935.

25. Shen, J.; Song, R.; Hodges, T.R.; Heimberger, A.B.; Zhao, H. Identification of metabolites in plasma for predicting survival in glioblastoma. Mol. Carcinog. 2018, 57, 1078-1084. [CrossRef] [PubMed]

26. Zhang, W.; Jiang, H.; Jin, M.; Wang, Q.; Sun, Q.; Du, Y.; Gao, L.; Xu, H. UHPLC-Q-TOF-MS/MS based screening and identification of the metabolites in vivo after oral administration of betulin. Fitoterapia 2018, 127, 29-41. [CrossRef] [PubMed]

27. Zeng, X.; Su, W.; Zheng, Y.; Liu, H.; Li, P.; Zhang, W.; Liang, Y. UFLC-Q-TOF-MS/MS-Based Screening and Identification of Flavonoids and Derived Metabolites in Human Urine after Oral Administration of Exocarpium Citri Grandis Extract. Molecules 2018, 23, 895. [CrossRef] [PubMed] 
28. Zhang, X.; Liao, M.; Cheng, X.; Liang, C.; Diao, X.; Zhang, L. Ultrahigh-performance liquid chromatography coupled with triple quadrupole and time-of-flight mass spectrometry for thescreening and identification of the main flavonoids and their metabolites in rats after oral administration of Cirsium japonicum DC. extract. Rapid Commun. Mass Spectrom. 2018, 30, 1451-1461.

29. Li, Y.; Peng, Y.; Wang, M.; Zhou, G.; Zhang, Y.; Li, X. Rapid screening and identification of the differences between metabolites of Cistanche deserticola and C. tubulosa water extract in rats by UPLC-Q-TOF-MS combined pattern recognition analysis. J. Pharm. Biomed. Anal. 2016, 131, 364-372. [CrossRef] [PubMed]

30. Li, C.; Qi, L.; Li, P.; Wen, X.; Zhu, Y.; Liu, E.; Gong, Z.; Yang, X.; Ren, M.; Li, Y.; et al. Identification of metabolites of Danggui Buxue Tang in rat urine by liquid chromatography coupled with electrospray ionization time-of-flight mass spectrometry. Rapid Commun. Mass Spectrom. 2010, 23, 1977-1988. [CrossRef] [PubMed]

31. Li, H.; Sun, J.; Xie, H. Study on absorption mechanism of ginsenoside Rg 1 using rat everted gut sac. Chin. J. Clin. Pharm. Ther. 2004, 9, 510-513.

32. Gui, J.; Yang, W.; Li, Y. Simultaneous enantiomer determination of 20 (R)- and 20 (S)-ginsenoside-Rg2 in rat plasma after intravenous administration using HPLC method. J. Chromatogr. B 2007, 850, 1-6. [CrossRef] [PubMed]

33. Cai, Z.; Qian, T.; Wong, R.N.S.; Jiang, Z. Liquid chromatography-electrospray ionization mass spectrometry for metabolism and pharmacokinetic studies of ginsenoside Rg3. Anal. Chim. Acta 2003, 492, 283-293. [CrossRef]

34. Santagata, S.; Di, C.E.; Carducci, C. Development of a new UPLC-ESI-MS/MS method for the determination of biopterin and neopterin in dried blood spot. Clin. Chim. Acta 2017, 466, 145-151. [CrossRef] [PubMed]

35. Wang, L.; Sang, M.; Liu, E.; Banahene, P.O.; Zhang, Y.; Wang, T. Rapid profiling and pharmacokinetic studies of major compounds in crude extract from Polygonum multiflorum by UHPLC-Q-TOF-MS and UPLC-MS/MS. J. Pharm. Biomed. Anal. 2017, 140, 45-61. [CrossRef] [PubMed]

36. Gao, J.; Qiu, Y.; Chen, J.; Mu, S.; Sun, L. Simultaneous determination of nineteen major active compounds in Qiangshen tablet by UPLC-ESI-MS/MS. J. Pharm. Biomed. Anal. 2016, 128, 519-527. [CrossRef] [PubMed]

37. Zhang, X.; Guo, Z.; Li, J.; Ito, Y.; Sun, W. A new quantitation method of protodioscin by HPLC-ESI-MS/MS in rat plasma and its application to the pharmacokinetic study. Steroids 2016, 106, 62-69. [CrossRef] [PubMed]

38. Sun, Y.; Xue, J.; Li, B.; Xue, J.; Li, B.; Lin, X.; Wang, Z. Simultaneous quantification of triterpenoid saponins in rat plasma by UHPLC-MS/MS and its application to a pharmacokinetic study after oral total saponin of Aralia elata leaves. J. Sep. Sci. 2016, 39, 4360-4368. [CrossRef] [PubMed]

39. Wang, C.; Zhang, N.; Wang, Z.; Qi, Z. Rapid characterization of chemical constituents of Platycodon grandiflorum and its adulterant Adenophora stricta by UPLC-QTOF-MS/MS. J. Mass Spectrom. 2017, 52, 643-656. [CrossRef] [PubMed]

Sample Availability: Samples of the compounds 12-riboside-pseudoginsengenin DQ, 20R-panaxadiol and pseudoginsengenin DQ are available from the authors.

(C) 2018 by the authors. Licensee MDPI, Basel, Switzerland. This article is an open access article distributed under the terms and conditions of the Creative Commons Attribution (CC BY) license (http://creativecommons.org/licenses/by/4.0/). 